\title{
LEGITIMATE CUSTOMER CONSEQUENCES DERIVING FROM CUSTOMER-ORIENTED DEVIANCE
}

\author{
Achilleas Boukis, Sussex University, $\mathrm{UK}^{1)}$ \\ Kalliopi Chatzipanagiotou, Glasgow University, $\mathrm{UK}^{2)}$
}

\begin{abstract}
Acknowledging the developments in the constructive employee deviance stream (Leo and Russell-Bennett, 2014), which denote that although employees may depart from workgroup hypernorms, their behaviour might still have pro-customer intentions (Vadera, Pratt and Mishra, 2013), this research illuminates deviant employee-customer encounters and grows the ongoing discussion on the impact of employee customeroriented deviance on various customer outcomes. Customer-oriented deviance (COD) is a form of pro-social behaviour which occurs when the employee deviates from organizational norms, defying organizational protocol and higher authority for the sake of the customer who is the main beneficiary of this behaviour.
\end{abstract}

Indeed, scarce evidence explores how customer-oriented deviance during the service encounter affects customers' psychological state as well as whether the psychological consequences deriving from employee deviance which actually render the customer more prone to reciprocally respond the employee or the organization with some kind of citizenship behaviour (Hochstein, Bonne and Clark, 2015), this study addresses the impact of three types of customer-oriented deviance on post-deviant customer evaluations.

To address these issues, an experimental design with a $3 \times 2$ between-subjects design is adopted. The independent variables manipulated are three types of COD and also whether the customer participates (or not) to the solution of the problem that (s)he is currently facing. In particular, the impact of three types of customer-oriented deviance (i.e. deviant service adaptation, service communication and use of resources) on customer's distributive, interactional and procedural justice (cognitive outcomes) and customer's emotional state (affective outcome) is considered.

This study advances current knowledge in three ways. First, it proposes that postdeviant customer consequences are both cognition- and emotion-driven, deepening the empirical understanding of the role of customer's perceived justice and emotional state as a result of COD. Results also uncover the importance of customer participation during COD and its corresponding impact on customer encounter outcomes. The social exchange and the equity theory are extended and set as the theoretical link between customer-oriented deviance and customer's response to the organization and the employee. 
Keywords: customer-oriented deviance, perceived justice, customer participation

\section{References}

Hochstein, B. W., Bonney, L., \& Clark, M. (2015). Positive and Negative Social Reactions to Salesperson Deviance. Journal of Marketing Theory and Practice, $\mathrm{Vol}$ 23 No 3, pp. 303-320.

Leo, C., \& Russell-Bennett, R. (2014). Developing a multidimensional scale of customer-oriented deviance (COD). Journal of Business Research, 67(6), 12181225.

Vadera, A. K., Pratt, M. G., \& Mishra, P. (2013). Constructive deviance in organizations integrating and moving forward. Journal of Management, 0149206313475816. 